\title{
Psychosocial, behavioural, and health determinants of successful smoking cessation: a longitudinal study of Danish adults
}

\author{
Merete Osler, Eva Prescott
}

\begin{abstract}
Objective-To examine the factors that determine whether or not smokers become long-term quitters, and to study whether determinants of successful cessation differ with levels of motivation to stop.

Design-In a cohort of men and women, aged 30-60 years at first examination in 1982/1984, smoking behaviour was evaluated from questionnaires at baseline and at follow up 10 years later.

Setting-County of Copenhagen, Denmark

Participants-2554 subjects from the original sample of 4581 were successfully followed. This study deals with the 1365 subjects who were smokers at the first examination.
\end{abstract}

Main outcome measure-Smoking status (abstinent for one year or more) at follow up.

Results-At follow up $\mathbf{1 5 \%}$ of the baseline smokers had been abstinent for one year or more. In multivariate analysis, successful smoking cessation was associated with older age, high social status, low prior tobacco consumption, baseline motivation to stop smoking, and having a non-smoking spouse/cohabitant. The same result was obtained when the analyses were repeated separately for smokers with and without motivation to stop.

Conclusions-Smokers motivated to stop are more likely to quit and remain abstinent than smokers with no such motivation. Age, social status, spouse/ cohabitant's smoking behaviour, and the daily consumption of tobacco predict success in smoking cessation, irrespective of smokers' former motivation to stop.

(Tobacco Control 1998;7:262-267)

Medicine an

Psychosocial Health, Institute of Public

Health, University of

Copenhagen, Denmark

M Osler

Institute of Preventive Medicine, Copenhagen Hospital Corporation, Copenhagen Municipal Hospital

E Prescott

Correspondence to: Dr M Osler, Department of Social Medicine and Social Medicine and sychosocial Health, University of Copenhagen Blegdamsvej 3, $2200 \mathrm{~N}$ Copenhagen, Denmark M.Osler@socmed.ku.dk
Keywords: smoking cessation predictors, Denmark

\section{Introduction}

Smoking behaviour has enormous implications for the individual and for public health. Smoking accounts for about $30 \%$ of all deaths, and is one of the most important preventable causes of premature death in northern Europe today. ${ }^{1}$ In Denmark, the prevalence of smoking in men has decreased from $78 \%$ in 1953 to $45 \%$ in 1993, whereas in women it has remained almost constant at about $40 \% .^{2}$ Despite its decline, the prevalence of smoking is still higher in Denmark than in other countries in western Europe and the United States. Consequently, the prevention of smoking is given high priority. Since the early 1950s, the mass media in most Westernised countries have frequently highlighted the health consequences of smoking, and today $30-60 \%$ of smokers wish to stop. ${ }^{3}$ Individual smoking cessation programmes have received attention as an antismoking strategy. In setting up smoking cessation programmes it would be helpful to predict which smokers are unlikely to be successful quitters, and thereby identify those who need special attention.

The stages-of-change model, which views smoking behaviour change as a series of actions or events, is increasingly used in health promotion today. ${ }^{5}$ Briefly, this model proposes that stages of behaviour change can be conceptualised in at least four phases: precontemplation, in which there is no thought or awareness of the need to change behaviour; contemplation, seriously thinking about the problem and the possibility of change; action, modification of behaviour during a period from 1 to 6-12 months; and successful maintenance of the changed behaviour for an extended period of time. ${ }^{6}$

Previous studies on smoking cessation have most consistently associated successful quitting with older age, ${ }^{4-15}$ high education or socioeconomic status, ${ }^{4-17}$ low prior consumption of cigarettes, ${ }^{9-11}{ }^{13}{ }^{15-19}$ and living with a non-smoking spouse/cohabitant. ${ }^{1011} 13161719$ Furthermore, low consumption of coffee, ${ }^{16} 19$ has predicted success in smoking cessation in studies of pregnant women. The extent to which these factors determine prolonged tobacco abstinence has been assessed infrequently, as most previous studies on smoking cessation have been cross-sectional in design. ${ }^{12}$ 13-17 19-20 Although the stages-ofchange model has become widely adopted to help understand the cessation process, ${ }^{6}$ few have studied whether the level of motivation to stop predicts smoking cessation, ${ }^{6} 182122$ and the model's validity has been questioned. ${ }^{18}$ Farkas et al showed that in a large sample of smokers randomly selected from the population of Californian smokers, the stage of change was a significant predictor of smoking status $1-2$ years later. However, stage of change was not an independent predictor when used in a multivariate analysis with measures of addiction (including quitting history and baseline cigarette consumption), and these factors were better predictors of future smoking status 
Table 1 Smoking behaviour of smokers at baseline (1982/1984) and follow up (1993/1994). Values are numbers

\begin{tabular}{|c|c|c|c|c|}
\hline \multirow[b]{2}{*}{ Smoking behaviour } & \multirow{2}{*}{$\begin{array}{l}\text { All smokers } \\
(1982 / 1984)\end{array}$} & \multicolumn{2}{|c|}{ Former smoker (1993/1994) } & \multirow{2}{*}{$\begin{array}{l}\text { Current smoker } \\
\text { (1993/1994) }\end{array}$} \\
\hline & & $<1$ year* & $\geqslant 1$ yeart & \\
\hline \multicolumn{5}{|c|}{ Contemplation stage $(1982 / 1984)$} \\
\hline Wish to stop & 126 & 1 & 12 & 113 \\
\hline Tried to stop & 393 & 20 & 74 & 299 \\
\hline Wish and tried to stop & 341 & 17 & 56 & 268 \\
\hline \multicolumn{5}{|c|}{ Precontemplation stage $(1982 / 1984)$} \\
\hline Didn't wish or try to stop & 505 & 14 & 60 & 431 \\
\hline Total & $1365(100 \%)$ & $52(5 \%)$ & $202(15 \%)$ & $1111(80 \%)$ \\
\hline
\end{tabular}

${ }^{\star}$ Omitted from statistical analyses.

†Successful quitters (outcome measure).

than was stage of change. ${ }^{18}$ However, the multivariate analysis by Farkas et al did not include other known predictors of cessation such as sociodemographic variables (gender, age, and education). Another problem is that most studies have ignored the distinction between smokers who are motivated to stop and those who are not, thereby perhaps grouping smokers with different behaviour and attitudes in one group. ${ }^{523}$ This may obscure important predictors of smoking cessation in the different stages of behaviour change.

In a follow-up study of a cohort of randomly selected adult men and women, we examined the psychosocial, behavioural, and health factors that determined whether smokers had become continuous ex-smokers during the 10 years of follow up. We also studied whether separate analyses of smokers who had tried or wished to stop smoking at baseline (in the contemplation stage) and those who had not (in the precontemplation stage) changed the determinants of successful cessation.

\section{Methods}

SUBJECTS

The study included 4581 Danish citizens aged $30,40,50$ and 60 years, randomly selected from the general population. Of them 3608 $(79 \%)$ attended a health examination and completed a standardised questionnaire. The study was part of the Danish MONICA project (an international study conducted under the auspices of the World Health Organisation to monitor trends in and determinants of mortality from cardiovascular disease), and was carried out in collaboration with the Glostrup Population Studies in Copenhagen. The study was approved by the Ethics Committee of the County of Copenhagen. Examinations took place between November 1982 and February 1984.

After 10 years, the 4130 subjects from the original sample who were still alive and had an address in Denmark were invited to a follow-up examination, which 2656 attended. The results are based on the 2554 subjects with complete smoking information at both examinations. Among the 1054 subjects who participated in the first but not in the second examination, the prevalence of smoking was higher, they were older, and more belonged to the lowest social class than among the subjects who attended both examinations. Rate of participation at follow up did not differ between smokers with and without previous attempts to quit.

\section{OUESTIONNAIRE}

All participants filled out an extensive questionnaire on psychosocial factors, behaviour, and health at the baseline and follow-up examinations.

Smoking behaviour

Smoking behaviour was assessed by the questions: "Do you smoke?" and, if the answer was no: "Have you smoked previously?". Current and former smokers were asked about their present or past average daily consumption of tobacco, including cigarettes, cheroots, cigars, and pipe tobacco. Converted into grams of tobacco, a cigarette equals $1 \mathrm{~g}$, a cheroot equals $2 \mathrm{~g}$, and a cigar equals $5 \mathrm{~g}$. Former smokers were also asked what year and why they had stopped smoking. Participants were asked for how many years they had smoked, whether they had ever tried to stop smoking, and, if so, how many times. Later in the questionnaire smokers were also asked whether they seriously wished to stop smoking. In the present study the contemplation stage was defined as smokers who at baseline reported that they seriously wished to stop or had made one or more (self-defined) attempts to stop smoking $(n=860)$.

The initial study group consisted of the 1365 participants who were smokers at baseline. The outcome variable was successful quitting (maintenance stage), defined as having abstained from smoking for a year or more (table 1). The 52 smokers who had been abstinent for less than a year were omitted from the statistical analyses.

\section{Psychosocial factors}

Socioeconomic status was determined using the method of the Danish National Institute of Social Research on the basis of type of employment, education, and number of subordinates. ${ }^{24}$ The participants were classified into five social strata, with I as the highest and $\mathrm{V}$ as the lowest. The strata were defined as follows.

I-self-employed with at least 21 employees, or white-collar workers with at least 51 subordinates or an academic degree

II-self-employed with 6-20 employees, or white-collar workers with 11-50 subordinates or intermediate education

III-self-employed with 1-5 employees, or white-collar workers with 1-10 subordinates IV-self-employed without employees, or white-collar workers without subordinates or qualified work, or skilled blue-collar workers $\mathrm{V}$-unskilled blue-collar workers.

Recent unemployment was determined by the question: "How long have you been unemployed during the last 12 months?" Participants were also asked whether they felt busy in their everyday life (yes or no) or had any personal or economic problems (yes or no). Questions were asked on the smoking behaviour of spouse/cohabitant, children, parents, siblings, other family members, 
friends, and colleagues; awareness of tobacco advertisements; knowledge of diseases associated with smoking; attitude towards smoking cessation; and attitude toward health in general. A "knowledge score" was calculated on the basis of the six statements that smoking increases the risk of bronchitis, lung cancer, cancer of the mouth and throat, thrombosis, poor circulation, and impaired fitness. The score ranged from $0-6$, reflecting the number of agreements; scores of 4 and over were considered to be high. ${ }^{25}$

\section{Other health behaviours}

The questionnaire addressed a number of health behaviours besides smoking, such as physical activity during leisure-time and the consumption of beer, wine, spirits, and coffee.

Health status

Self-rated health status was assessed with the question: "How would you assess your present health in general?" Participants were asked to compare their physical condition with that of others of the same age. They were also asked whether a doctor had told them that they suffered from any diseases. Positive responses for ischaemic heart disease or bronchitis were used in this study. Body mass index (BMI) was calculated as weight divided by the square of the height. The anthropometric data were collected by nurses at the health examinations.

\section{STATISTICAL ANALYSES}

Univariate logistic regression was performed for each determinant to study its individual relation to status as a successful quitter or not. Multiple logistic regression analyses were carried out to estimate the effect of each individual variable, adjusting for the other variables in the model. The outcome variable was whether the respondent still smoked $(\operatorname{code}=$ 0 ) or was a successful quitter $(\operatorname{coded}=1)$. The independent variables in the first three models of the first step of the analysis were selected on the basis of previous studies on predictors of smoking cessation, ${ }^{4-20}$ and a theoretical framework describing human behaviour as

Table 2 Psychosocial determinants of successful smoking cessation

\begin{tabular}{|c|c|c|c|c|c|c|}
\hline Variable & No of smokers ${ }^{\star}$ & $\begin{array}{l}\text { Successful } \\
\text { cessation (\%) }\end{array}$ & Univariate $O R$ & $95 \% C I$ & Multivariate $+O R$ & $95 \% C I$ \\
\hline \multicolumn{7}{|l|}{ Environmental factors } \\
\hline \multicolumn{7}{|l|}{ Social group $\ddagger$} \\
\hline I-II & 242 & 25.6 & 1 & & 1 & \\
\hline III & 365 & 18.2 & 0.6 & $0.4-0.9$ & 0.7 & $0.4-1.2$ \\
\hline IV & 431 & 11.4 & 0.4 & $0.2-0.6$ & 0.4 & $0.2-0.7$ \\
\hline $\mathrm{V}$ & 275 & 9.1 & 0.3 & $0.2-0.5$ & 0.4 & $0.2-0.8$ \\
\hline \multicolumn{7}{|l|}{ Unemployed last year } \\
\hline Yes & 113 & 8.9 & 1 & & 1 & \\
\hline No & 1200 & 16.0 & 2.0 & $1.0-3.8$ & 2.5 & $1.2-3.7$ \\
\hline \multicolumn{7}{|l|}{ Feel busy } \\
\hline Yes & 712 & 14.6 & 1 & & 1 & \\
\hline No & 565 & 16.5 & 1.2 & $0.9-1.6$ & 1.3 & $0.9-2.0$ \\
\hline \multicolumn{7}{|l|}{ Economic problems } \\
\hline Yes & 226 & 12.8 & 1 & & 1 & \\
\hline No & 1086 & 15.9 & 1.3 & $0.8-2.0$ & 1.4 & $0.6-2.3$ \\
\hline \multicolumn{7}{|l|}{ Spouse smokes } \\
\hline Yes & 600 & 10.8 & 1 & & 1 & \\
\hline No & 469 & 23.7 & 2.6 & $1.8-3.5$ & 2.3 & $1.5-3.5$ \\
\hline No spouse/cohabitant & 227 & 10.6 & 1.0 & $0.6-1.6$ & 0.8 & $0.4-1.7$ \\
\hline \multicolumn{7}{|c|}{ Smokers among children, parents, siblings, other family, friends, colleagues } \\
\hline 0 or 1 & 258 & 22.5 & 1 & & 1 & \\
\hline 2 & 351 & 17.4 & 0.7 & $0.5-1.1$ & 1.1 & $0.6-1.6$ \\
\hline$\geqslant 3$ & 471 & 11.9 & 0.5 & $0.3-0.7$ & 0.7 & $0.4-1.2$ \\
\hline \multicolumn{7}{|l|}{ Personal factors } \\
\hline \multicolumn{7}{|l|}{ Sex } \\
\hline Men & 716 & 17.5 & 1 & & 1 & \\
\hline Women & 597 & 12.9 & 0.7 & $0.5-0.9$ & 0.7 & $0.4-1.0$ \\
\hline \multicolumn{7}{|l|}{ Age (years) } \\
\hline 30 & 397 & 16.8 & 1 & & 1 & \\
\hline 40 & 354 & 11.3 & 0.7 & $0.4-1.0$ & 0.5 & $0.4-0.8$ \\
\hline 50 & 352 & 13.1 & 0.8 & $0.5-1.2$ & 0.7 & $0.4-1.3$ \\
\hline 60 & 210 & 24.3 & 1.7 & $1.1-2.5$ & 1.7 & $1.0-3.3$ \\
\hline \multicolumn{7}{|l|}{ Personal problems } \\
\hline Yes & 225 & 15.6 & 1 & & 1 & \\
\hline No & 1087 & 15.4 & 1.3 & $0.8-1.9$ & 1.1 & $0.6-2.3$ \\
\hline \multicolumn{7}{|c|}{ Knowledge of diseases associated with smoking } \\
\hline High & 739 & 17.8 & 1 & & 1 & \\
\hline Low & 356 & 15.8 & 1.1 & $0.8-1.5$ & 1.4 & $0.9-2.1$ \\
\hline \multicolumn{7}{|l|}{ Believe it is healthy to stop smoking } \\
\hline Yes & 470 & 15.1 & 1 & & 1 & \\
\hline No & 825 & 15.5 & 1.0 & $0.7-1.4$ & 1.1 & $0.7-1.6$ \\
\hline \multicolumn{7}{|l|}{ Stage of change (motivation to stop) } \\
\hline $\begin{array}{l}\text { Precontemplation (did not wish } \\
\text { or try to quit) }\end{array}$ & 491 & 12.2 & 1 & & 1 & \\
\hline $\begin{array}{l}\text { Contemplation (wished or tried } \\
\text { to quit) }\end{array}$ & 822 & 17.3 & 1.5 & $1.1-2.1$ & 2.0 & $1.3-3.1$ \\
\hline \multicolumn{7}{|l|}{ Health attitude/own effort $\$$} \\
\hline Important & 729 & 15.8 & 1 & & 1 & \\
\hline Some importance & 434 & 16.6 & 1.1 & $0.8-1.5$ & 1.2 & $0.8-1.7$ \\
\hline No importance & 65 & 9.2 & 0.5 & $0.2-1.3$ & 0.2 & $0.1-1.1$ \\
\hline
\end{tabular}

* Number may vary because of missing data.

$\mathrm{OR}=$ odds ratios; $\mathrm{CI}=$ confidence intervals

tAll the covariates in the table were included in the model.

†The participants were classified into five social strata, with I as the highest and V as the lowest (see text for definitions).

§Subjects were asked how important they believe their own effort is for staying healthy. 
Table 3 Behavioural determinants of successful smoking cessation

\begin{tabular}{|c|c|c|c|c|c|c|}
\hline Variables & No of smokers * & $\begin{array}{l}\text { Successful } \\
\text { cessation (\%) }\end{array}$ & Univariate $O R$ & $95 \% C I$ & Multivariate $f O R$ & $95 \% C I$ \\
\hline \multicolumn{7}{|c|}{ Amount smoked (g/day) } \\
\hline $0-9$ & 636 & 20.8 & 1 & & 1 & \\
\hline$\geqslant 10$ & 677 & 10.4 & 0.4 & $0.3-0.6$ & 0.5 & $0.3-0.8$ \\
\hline \multicolumn{7}{|l|}{ Years smoked } \\
\hline $0-14$ & 304 & 20.4 & 1 & & 1 & \\
\hline$\geqslant 15$ & 1009 & 13.9 & 0.6 & $0.5-0.9$ & 0.4 & $0.3-0.6$ \\
\hline \multicolumn{7}{|c|}{ Days a week having five or more drinks of alcohol } \\
\hline 0 & 1093 & 16.3 & 1 & & 1 & \\
\hline$\geqslant 1$ & 219 & 11.0 & 0.6 & $0.4-1.0$ & 0.7 & $0.5-1.1$ \\
\hline \multicolumn{7}{|c|}{ Cups of coffee daily } \\
\hline 0 & 63 & 11.1 & 1 & & 1 & \\
\hline $1-4$ & 361 & 18.6 & 1.8 & $0.8-4.2$ & 1.9 & $0.8-4.2$ \\
\hline$\geqslant 5$ & 889 & 14.4 & 1.8 & $0.6-3.0$ & 1.5 & $0.7-3.5$ \\
\hline \multicolumn{7}{|l|}{ Leisure activity } \\
\hline Low & 355 & 13.0 & 1 & & 1 & \\
\hline Moderate/high & 958 & 16.1 & 1.3 & $0.9-1.9$ & 1.5 & $0.8-1.9$ \\
\hline
\end{tabular}

^Number may vary because of missing data.

$\mathrm{OR}=$ odds ratio; $\mathrm{CI}=$ confidence intervals.

tGender, age, and the five behavioural covariates were included in the model.

being reciprocally determined by personal factors and the environment in which the person lives. ${ }^{26}$ The analyses were carried out for the whole group $(n=1313)$, and separately for smokers in the precontemplation and contemplation stages. The final model was built through sequential model testing after the removal and addition of each non-significant predictor, starting with a model including all the independent variables. Ninety-five per cent confidence intervals (CIs) around estimates were computed. Models fit were tested by the Hosmer-Lemeshow $\chi^{2}$ test. The data were grouped in percentiles of the fitted values. The test statistics computed from the observed and expected frequencies indicated reasonable fits. Data analyses were performed using STATA. ${ }^{27}$

\section{Results}

During the study period, the overall proportion of smokers in this population $(n=2554)$ was reduced from $52 \%$ to $46 \%$. Smoking behaviour in $1982 / 1984$ is contrasted, in table 1 , with the smoking status of the same subjects 10 years later. Of the 1365 smokers at baseline, 15\% had become ex-smokers for a year or more at follow up. The quit rate was nearly constant over time, and the average annual number of quitters was 20 (1.5\% per year). The success rate was lowest $(10 \%)$ among those who only wished to stop smoking, and highest among those who wished and tried to stop smoking $(19 \%)$. Among precontemplators the quit rate was $12 \%$. Ex-smokers' main reasons for quitting smoking were to get more healthy $(66 \%)$, health problems $(32 \%)$, for the sake of their family (23\%), or economic factors (19\%). Most ex-smokers had more than one reason for quitting.

Table 2 presents a summary of the univariate and multivariate analyses of the psychosocial determinants of successful smoking cessation. The multivariate analysis showed that older age, high socioeconomic status, no unemployment during the last year, having a non-smoking spouse/cohabitant, and motivation to stop were associated with successful smoking cessation. Rates of success decreased, continuously, with decreasing social status. When the contemplation stage was divided into the original questions on quit attempt and wish to stop, previous quit attempts predicted

Table 4 Health determinants of successful smoking cessation

\begin{tabular}{|c|c|c|c|c|c|c|}
\hline Variables & No of smokers * & $\begin{array}{l}\text { Successful } \\
\text { cessation (\%) }\end{array}$ & Univariate $O R$ & $95 \% C I$ & Multivariatef $O R$ & $95 \% C I$ \\
\hline \multicolumn{7}{|c|}{ Self-rated health status } \\
\hline Good & 1082 & 15.0 & 1 & & 1 & \\
\hline Fair & 124 & 19.0 & 1.3 & $0.9-2.1$ & 1.2 & $0.7-2.0$ \\
\hline Poor & 27 & 7.4 & 0.6 & $0.1-1.9$ & 0.2 & $0.1-2.5$ \\
\hline \multicolumn{7}{|c|}{ Physical performance compared with contemporaries } \\
\hline Same & 933 & 14.7 & 1 & & 1 & \\
\hline Better & 249 & 18.5 & 1.3 & $0.9-1.9$ & 1.5 & $0.9-2.2$ \\
\hline Poorer & 129 & 14.0 & 0.7 & $0.6-1.6$ & 0.8 & $0.4-1.6$ \\
\hline \multicolumn{7}{|c|}{ Body mass index $\left(\mathrm{kg} / \mathrm{m}^{2}\right)$} \\
\hline$<20$ & 136 & 15.4 & 1 & & 1 & \\
\hline $20-24$ & 620 & 15.2 & 1.0 & $0.6-1.6$ & 0.8 & $0.4-1.5$ \\
\hline $25-29$ & 249 & 16.1 & 1.0 & $0.6-1.9$ & 0.8 & $0.3-1.5$ \\
\hline$\geqslant 30$ & 56 & 21.4 & 1.5 & $0.7-3.3$ & 1.4 & $0.5-3.2$ \\
\hline \multicolumn{7}{|c|}{ Hospitalised within last year } \\
\hline Yes & 768 & 15.0 & 1 & & 1 & \\
\hline No & 545 & 16.0 & 1.1 & $0.8-1.5$ & 1.0 & $0.7-1.4$ \\
\hline \multicolumn{7}{|c|}{ Angina pectoris } \\
\hline Yes & 10 & 20.0 & 1 & & 1 & \\
\hline No & 1303 & 15.4 & 0.7 & $0.2-3.4$ & 0.8 & $0.2-4.6$ \\
\hline \multicolumn{7}{|l|}{ Bronchitis } \\
\hline Yes & 152 & 11.8 & 1 & & 1 & \\
\hline No & 1161 & 15.9 & 1.3 & $0.8-2.4$ & 1.3 & $0.7-2.3$ \\
\hline
\end{tabular}

$\star$ Number may vary because of missing data.

$\mathrm{OR}=$ odds ratios $; \mathrm{CI}=$ confidence intervals

tGender, age, and the six health covariates were included in the model. 
Table 5 Significant predictors of successful smoking cessation in the final multivariate model with the 22 psychosocial, behavioural, and health covariates

\begin{tabular}{|c|c|c|}
\hline Variables & $\begin{array}{l}\text { Multivariate } \\
\text { OR }\end{array}$ & $95 \% C I$ \\
\hline \multicolumn{3}{|l|}{ Social group $\star$} \\
\hline I-II & 1 & \\
\hline III & 0.77 & $0.43-1.33$ \\
\hline VI & 0.40 & $0.17-0.76$ \\
\hline $\mathrm{V}$ & 0.47 & $0.22-0.88$ \\
\hline \multicolumn{3}{|l|}{ Spouse smokes } \\
\hline Yes & 1 & \\
\hline No & 2.12 & $1.40-3.50$ \\
\hline No spouse/cohabitant & 0.82 & $0.35-1.98$ \\
\hline \multicolumn{3}{|l|}{ Age (years) } \\
\hline 30 & 1 & \\
\hline 40 & 1.12 & $0.53-2.34$ \\
\hline 50 & 1.14 & $0.69-2.42$ \\
\hline 60 & 3.23 & $1.28-4.16$ \\
\hline \multicolumn{3}{|c|}{ Stage of change (motivation to stop) } \\
\hline $\begin{array}{l}\text { Precontemplation (did } \\
\text { not wish or try to quit) }\end{array}$ & Precontemplation (did & \\
\hline \multicolumn{3}{|l|}{ Contemplation (wished } \\
\hline \multicolumn{3}{|l|}{ Amount smoked (g/day) } \\
\hline $0-10$ & 1 & \\
\hline$\geqslant 10$ & 0.44 & $0.28-0.79$ \\
\hline Pseudo $R^{2}$ & 0.13 & \\
\hline \multicolumn{3}{|l|}{$\mathrm{p}$-Value } \\
\hline Hosmer-Lemeshow $\chi^{2}$ & 0.44 & \\
\hline
\end{tabular}

$\mathrm{OR}=$ odds ratios, $\mathrm{CI}=$ confidence intervals

*The participants were classified into five social strata, with I

as the highest and $\mathrm{V}$ as the lowest (see text for definitions).

successful cessation $(\mathrm{p}<0.01)$, whereas wish to stop did not $(p=0.64)$. Women were less likely than men to become quitters, although this gender difference did not quite reach statistical significance in the multivariate analysis.

Findings for the behavioural determinants of smoking cessation are shown in table 3 . In multivariate analyses with sex, age, and all behavioural variables in the model, the amount of tobacco smoked and the duration of smoking were strongly associated with successful smoking cessation, whereas the association with alcohol intake was not as strong.

The proportion of individuals who succeeded in stopping smoking did not vary significantly with any of the health variables, in either the univariate or multivariate analyses (table 4).

The variables that significantly predicted successful smoking cessation in the final model (table 5) were older age, high social status, non-smoking spouse/cohabitant, motivation to stop, and low prior tobacco consumption. Although the odds ratios for unemployment and duration of smoking did not change after adjustment for all the other covariates, they were not significant predictors $(p=0.10)$ in the final model, presumably because of loss of statistical power. We examined our data for interaction between amount of smoking and age but found no evidence for such an interaction with regard to success in quitting smoking. The same results were obtained when the analysis was repeated separately for smokers in the precontemplation and contemplation stages.

\section{Discussion}

In accordance with the findings of the most recent long-term studies, ${ }^{10}{ }^{11}$ we found that age, social class, and amount of smoking are important determinants of successful smoking cessation. In contrast to the findings of Farkas et $a l,{ }^{18}$ baseline motivation to stop smoking also predicted successful quitting even after adjustment for other known predictors of cessation. Of the two variables (previous quit attempt and desire to stop smoking) that we used to categorise smokers as precontemplators or contemplators, quitting history was the stronger predictor of successful cessation. This observation is in agreement with the results from the Multiple Risk Factor Intervention Trial. ${ }^{10}$ Our study further suggests that successful quitting among smokers in the precontemplation and contemplation stages is determined by the same factors (age, high social status, low prior tobacco consumption, and having a nonsmoking spouse/cohabitant).

During the 1960s male smokers had higher quitting rates than female smokers, but it appears that this gender difference decreased in the $1970 \mathrm{~s} .^{28}$ Indeed several studies similar to ours indicate that by the 1980s quitting rates were as high for women as for men. ${ }^{1128}$

Our study also showed that older smokers (60 years at baseline) have higher cessation rates compared with the younger age groups. Older smokers may have higher cessation rates because they are more likely to experience health problems, which make the risks associated with smoking more apparent, and health problems were often reported as a reason for stopping smoking. This seems to contradict the finding that self-rated health status was not associated with quitting rate, either with or without adjustment for age (table 4). However, the lack of association between health status and successful smoking cessation may be due to the long follow-up period in our study. It could be problematic if the sickest smokers (who may be the most successful quitters) were less likely to attend the follow up because they had died or become too ill to participate. Thus, the longitudinal analysis based on the Framingham Heart Study, with a shorter follow-up period, showed that recent hospitalisation and development of coronary heart disease were predictive of smoking cessation after two years. ${ }^{9}$

Having a non-smoking spouse/cohabitant was one of the factors most strongly associated with successful smoking cessation. This observation supports the notion that a close social network plays an important role in quitting smoking, and it is consistent with the assumption that the most common situations in which relapse occurs are social settings in which other smokers are present. ${ }^{2029}$

Social class was also a significant predictor of quitting, since fewer smokers in social groups IV and V had quit. Furthermore, rates of success were lower among subjects who had experienced recent unemployment. Possibly due to the small numbers of subjects, this covariate did not retain statistical significance in the multivariate analysis. However, other factors related to low social status did not predict smoking cessation either in bivariate or multivariate analyses. Jobs with high pace and low control have been associated with low cessation rates. ${ }^{29}$ We had no information on job 
demands, but feeling busy every day did not predict unsuccessful smoking cessation.

Similar to other studies, ${ }^{40}$ economic problems were cited as a motivation for quitting, but we found no association between economic problems and smoking cessation. However, the question on economic problems was not very specific, and furthermore financial problems are considered a private matter and therefore may have been underreported.

Our results might be biased by sample selection, misclassification, and confounding. Our study included many of the potentially important factors associated with smoking cessation, and multivariate analyses were used to adjust for confounding. With regard to sample selection, the participation rate in the study was relatively high, and the distribution of smokers was in accordance with smoking status in Denmark from official omnibus surveillance measures. ${ }^{2}$ Although those "who dropped out" differed from study participants in terms of age and smoking behaviour, this would not influence the results of our study unless those who dropped out differed with regard to the determinants and-independent of this-had higher (or lower) rates of successful smoking cessation.

However, the high rates of loss to follow up could affect the generalisation of our findings. Because subjects who were lost to follow up overrepresented persons with lower socioeconomic status, the study results may be less applicable to this population.

As for misclassification, our study collected data using a standardised questionnaire which several investigators have considered satisfactory for assessing smoking, other health behaviours, social conditions, and health status. ${ }^{31}$ Self-reporting is usually acceptable for determining smoking status in epidemiological studies, ${ }^{32}$ and self-reported smoking status was confirmed at the baseline examination by serum thiocyanate. ${ }^{33}$ There was a 10 -year lag between measurement of baseline exposures and the outcome at follow up, and dynamic measures such as stages of change may have changed during that period. We cannot exclude that smokers classified as precontemplators became motivated shortly after baseline data were collected. If such misclassifications occurred independently of quitting success, this would tend to underestimate the true association; consequently, the association we observed would not have been spurious.

In conclusion our study shows that besides motivation to stop, age, social status, spouse/cohabitant's smoking behaviour, and the daily consumption of tobacco are significant predictors of successful quitting. These factors predict cessation irrespective of smokers' baseline motivation to stop, and should be considered in setting up smoking cessation programmes.

This project was supported by grants from the Danish Health Development Foundation, the Danish Cancer Association, and the Danish Heart Foundation.
1 Bartecchi CE, MacKenzie TD, Schrier RW. The human costs of tobacco use. New Engl f Med 1994;330:307-11.

2 Nielsen PE, S $\notin$ rensen JF. Danskernes rygevaner 19881993. [Changes in smoking habits in the Danish population 1988-1993.] Ugeskr Laeger 1995;157:3451-6. 3 Meillier L, Osler M, Sabroe S, et al. Stages of change in smoking habits and reactions to health education material about smoking. Public Health 1998. In press.

4 Hatziandreu EJ, Pierce JP, Lefkopoulou M, et al. Quitting smoking in the United States in 1986. I Natl Cancer Inst 1990;82:1402-6.

5 Maibach E, Pauott RL. Designing health messages. Approaches from communication theory and public health. Coarsegold, California: Sage, 1993.

6 Prochaska JO, DiClimente CC, Velicer WF, et al. Standardized, individualized, interactive, and personalized self-help
programs for smoking cessation. Health Psychol 1993; 12:399-405.

7 Björnson W, Rand C, Connett JE, et al. Gender differences in smoking cessation after 3 years in the lung health study. Am f Public Health 1995;85:223-30.

8 Coambs RB, Kozlowski LT. Age interacts with heaviness of smoking in predicting success in cessation of smoking. Am f Epidemiol 1992;135:240-46.

9 Freund KM, Agostino RBD, Belanger AJ, et al. Predictors of smoking: the Framingham study. Am f Epidemiol 1992; 135:957-64.

10 Hymowitz N, Sexton M, Ockene J, et al. Baseline factors associated with smoking cessation and relapse. Prev Med 1991;20:590-601.

11 Tillgren P, Haglund BJA, Lundberg $M$, et al. The sociodemographic pattern of tobacco cessation in the 1980s: results from a panel study of living condition survey in Sweden. F Epidemiol Commun Health 1996;50:625-30.

2 Gilpin EA, Pierce JP, Goodman J, et al. Reasons smokers give for stopping smoking: do they relate to success in stopping? Tobacco Control 1992;1:256-63.

13 Chnattingius S, Lindmark G, Meirik O. Who continues to smoke while pregnant? F Epidemiol Commun Health 1992; 46:218-21.

14 Dejin-Karlsson E, Hanson BS, Östergren P, et al. Psychosocial resources and persistent smoking in early pregnancy-a population study of women in their first pregnancy-a population study of women in their first pregnancy in

15 Mas R, Escriba V, Colomer C. Who quits smoking during pregnancy? Scand f Soc Med 1996;24:102-6.

16 Olsen J. Predictors of smoking cessation in pregnancy. Scand f Soc Med 1993;3:197-202.

17 Severson HH, Andrews JA, Lichtenstein E, et al. Predictors of smoking during and after pregnancy: a survey of mothers and newborns. Prev Med 1995;24:23-8.

18 Farkas AJ, Pierce JP, Zhu S, et al. Addiction versus stages of change models in predicting smoking cessation. Addiction 1996;91:1271-80.

19 Wisborg K, Henriksen T, Hedegaard M, et al. Rygeophør blandt gravide. [Smoking cessation among pregnant blandt gravide. [Smoking cessation a

20 Curry SJ, McBride CM. Relapse prevention for smoking cessation: review and evaluation of concepts and interventions. Annu Rev Public Health 1994;15:345-66.

21 Prochaska JO, Velicer WF, Guadagnoli E, et al. Patterns of change: dynamic typology applied to smoking cessation. Multivar Behav Res 1991;26:83-107.

22 Lichtenstein E, Lando HA, Nothwehr F. Readiness to quit as a predictor of smoking changes in the Minnesota Heart Health Programme. Health Psychol 1994;13:393-6.

23 Unger JB. Stages of change of smoking cessation: relationship with other health behaviors. Am $f$ Prev Med 1996;12:134-8.

24 Enevoldsen B, Michelsen N, Friis-Hasche E, et al. Sociale klassifikationer. [Social classifications.] Ugeskr Lceger 1980; 142:544-50.

25 Osler M, Kirchhoff M. Smoking behaviour in Danish adults from 1982 to 1992. Public Health 1995;109:245-50.

26 Aarø LE. Health behaviour and socioeconomic status. A survey among the adult population in Norway (dissertation). Bergen, Norway: Faculty of Psychology, University of Bergen, 1986.

27 Stata Statistical Software: release 5.0. College Station, Texas: Stata Corporation, 1997.

28 Waldron I. Patterns and causes of gender differences in smoking. Soc Sci Med 1991;32:989-1005.

29 Syme SL, Alcalay R. Control of cigarette smoking from a social perspective. Annu Rev Public Health 1982;3:179-99.

30 Osler M, Rasmussen NK, Lous J. Voksne danskeres rygevaner. Adfærd og holdning i relation til forebyggelse af hjerte-karsygdomme. [Adults' smoking habits. Behaviour and attitudes in connection with prophylaxis of cardiovascular disease.] Ugeskr Laeger 1992;154:543-8.

31 Rasmussen NK. Nordic health and morbidity surveys. Copenhagen: DIKE, 1984;9-157.

32 Patrick DL, Cheadle AC, Thompson DC, et al. The validity of self-reported smoking: a review and meta-analysis. $A m \mathcal{F}$ Public Health 1994;84:1086-93.

33 Kirchhoff M. Hjerte-karsygdommenes udbredelse. Sociale og psykosociale forskelle i risikofaktorernes fordeling. [Cardiovascular diseases. Social and psychosocial differences in the distribution of risk factors.] Copenhagen: Glostrup Population studies, 1986. 